\title{
Expression of interleukin (IL)-11 and IL-11 receptor in human colorectal adenocarcinoma: IL-11 up-regulation of the invasive and proliferative activity of human colorectal carcinoma cells
}

\author{
AYUMI YOSHIZAKI*, TOSHIYUKI NAKAYAMA*, KAZUYUKI YAMAZUMI, \\ YUICHI YAKATA, MITSURU TABA and ICHIRO SEKINE \\ Department of Tumor and Diagnostic Pathology, Nagasaki University \\ Graduate School of Biomedical Sciences, Nagasaki, Japan
}

Received April 20, 2006; Accepted June 19, 2006

\begin{abstract}
Previous investigations have shown that interleukin (IL)-11/IL-11 receptor $\alpha$-chain (IL-11R $\alpha$ ), a member of the PI3K, MAPK and JAK-STAT activating family of cytokines/ receptors, correlates with the regulation of tumor progression. In this study, we established the IL-11/IL-11R $\alpha$ expression profile in human colorectal adenocarcinoma (CRC) and clarified its signaling pathway and role in the invasion activity of CRC cell lines. To elucidate the role of IL-11/ IL-11R $\alpha$, we examined 103 cases of CRC and 24 cases of colorectal adenoma by immunohistochemistry. In addition, we investigated the invasive activity of cell signaling pathway of CRC cell lines. The IL-11R $\alpha$ expression was correlated with tumor invasion and lymphatic infiltration ( $p<0.01$, respectively). Recombinant human IL-11 (rhIL-11) promoted the migration and proliferation of HT-29 cells and activated the PI3K and p44/p42 MAPK pathways. Wortmannin, a PI3K inhibitor, and PD98059, a p44/p42 MAPK inhibitor, significantly reduced the promotion of invasion and proliferation activity by rhIL-11, respectively. In summary, the IL-11R $\alpha$ expression was correlated with clinicopathological features and IL-11 promoted the invasion via the PI3K and up-regulated the proliferation via the p44/p42 MAPK in CRC cells. These findings suggested that the IL-11/IL-11R pathway plays an important role in the progression of CRC.
\end{abstract}

\section{Introduction}

Colorectal adenocarcinoma (CRC) is one of the most common neoplasms and is a significant cause of morbidity and mortality

Correspondence to: Dr Toshiyuki Nakayama, Department of Tumor and Diagnostic Pathology, Nagasaki University Graduate School of Biomedical Sciences, 1-12-4 Sakamoto, Nagasaki 852-8523, Japan

E-mail: toshi-n@nagasaki-u.ac.jp

${ }^{*}$ Contributed equally

Key words: IL-11, IL-11 receptor, PI3 kinase, MAP kinase, colon cancer in the world (1). The occurrence and progression of cancer is suggested to be related to a series of genetic events affecting the structure and/or expression of a number of oncogenes, anti-oncogenes and growth factors $(2,3)$. The deep-invasive carcinomas, such as CRC, have higher rates of lymph duct and venous invasion as well as lymph node metastasis than less invasive types of cancer (4). However, the mechanisms of invasion and metastasis of CRC have not been fully elucidated.

IL-11 is expressed by a variety of tissues, such as gut, brain, spinal cord neurons, and testes, and hence may have a physiological role in these organs (5). Breast cancer cells have been shown to secrete IL-11, and its possible role in bone metastasis and poor prognosis of breast cancer has been studied $(6,7)$. Recently, few reports have been published in the expression of IL-11 and IL-11R in colorectal cancer $(8,9)$. However, the role of IL-11 and IL-11R in colorectal cancer is still unclear.

Interleukin (IL)-11 was originally cloned as a mediator of plasmacytoma cell proliferation and was later found to exhibit a wide variety of biological effects in neural cells as well as in the hematopoietic and immune systems $(5,10)$. Although IL-11 shares gp130 as a signaling mechanism with several cytokines and growth factors, including IL-6, oncostatin M, leukemia inhibitory factor (LIF), and ciliary neurotrophic factor (CNTF), it also has unique biological actions (5).

The IL-11 receptor $\alpha$-chain (IL-11R $\alpha$ ) mediates the action of IL-11, a 19.1-KD pleiotropic cytokine that was initially cloned from a bone marrow stromal cell line (10). The hematopoietic effects of IL-11, which include stimulation of megakaryocyte maturation and platelet production, and growth stimulation of $\mathrm{CD} 34^{+}$hematopoietic progenitor cells, have been well studied. IL-11 has also been shown to mediate inhibition of adipogenesis, stimulation of osteoclasts, and cytoprotection of gut mucosa in gastric ulcers (11-14). The $\alpha$ subunit of the IL-11R is required for high affinity binding of the ligand; on ligand binding, gp130, the subunit responsible for signal transduction, is required for the formation of the receptor complex (15). It is known that IL-11R $\alpha$ associated gp130 undergoes homodimerization, as it does in the IL-6 receptor (16), but the nature of the signaling 
transduction systems used by IL- $11 \mathrm{R} \alpha$ is currently under investigation.

Protein kinases that have been implicated in IL-11-mediated signaling include phosphatidylinositol-3 kinase (PI3K), MAP kinase (MAPK), Jak1 and Jak2 receptor-associated kinases, src-family tyrosine kinases including $\mathrm{p} 60^{\text {src }}$ and $\mathrm{p} 62^{\text {yes }}(17,18)$. In this study, to investigate the PI3K pathway, the phosphorylation of P70 S6 ribosomal protein (P70 S6 RP) was investigated. P70 S6 RP is a downstream target of PI3Kgenerated signals and becomes activated after phosphorylation of Ser 235/236 (19-21). To study the effect of IL-11 on the MAPK pathway, the phosphorylation of P90 RSK and P38 MAPK was investigated. P90 RSK is a downstream target of p44/p42 mitogen-activated protein kinases and becomes activated after phosphorylation of Ser 380/363 (22-24). P38 MAPKs is a downstream target of MKK3 and SEK generated signals and becomes activated after phosphorylation of Thr180 and Tyr182 $(2,22,25)$. There is also evidence that the signal transduction and transcription factors (STAT) 1 and STAT3 are activated by IL-11R $\alpha$ (16).

In this study, we investigated the expression of IL-11 and IL-11R $\alpha$ in primary human CRC and attempted to determine, using cell line models, the biological actions of this cytokine in CRC.

\section{Materials and methods}

Clinical materials. Normal colorectal mucosa was obtained from a patient at autopsy. We studied 103 primary human CRC: 32 cases of submucosal invasion (T1), 9 cases of muscularis proprial invasion (T2), 43 cases of either subserosal or pericolic tissue invasion (T3), and 19 cases of invasion through the serosa or invasion of contiguous organs (T4). All tumor specimens were obtained from patients operated at Nagasaki University Hospital between 2001 and 2005. Each tumor was assigned a histological type and a grade of depth infiltration according to the TNM staging system $(26,27)$. We also classified all tumors into four groups based on the modified Dukes' staging system: according to this system, there were 40 cases of Dukes' A, limited to the bowel wall; 31 cases of Dukes' B, involved extramural spread; 28 cases of Dukes' C, involved the lymph nodes; and 4 cases of Dukes' D tumors, involved distant metastasis (28). We used 24 adenomas as benign lesions with moderate dysplasia. Normal colonic mucosal tissues were evaluated as normal controls. Each parameter was defined as 'present' when invasion was identified with certainty, but defined as 'absent' when either not observed at all or not observed with certainty. Lymph node metastasis was defined as 'present' only when histologically proven.

Immunohistochemical analysis. Formalin-fixed and paraffinembedded tissues were cut into $4 \mu \mathrm{m}$ sections, deparaffinized in xylene and rehydrated in phosphate-buffered saline. Deparaffinized sections were preincubated with normal bovine serum and then incubated overnight at $4^{\circ} \mathrm{C}$ with an optimal dilution $(0.1 \mu \mathrm{g} / \mathrm{ml})$ of a primary polyclonal rabbit antibody against human IL-11 (H-169) and IL-11R $\alpha$ (N-20). Each antibody was bought from Santa Cruz Biotechnology Inc. (Santa Cruz, CA, USA). The slides were sequentially incubated with a biotinylated and alkaline phosphataseconjugated goat anti-rabbit immunoglobulin $\mathrm{G}$ antibody, and the reaction products were visualized using diaminobenzidine (DAB, Dako, Carpinteria, CA, USA) with methyl green as a counterstain and 5-bromo-4-chloro-3-indolyl phosphate and nitroblue tetrazolium chloride (BCIP/NBT; Dako), respectively. Primary antibodies preabsorbed with excess recombinant peptides (Santa Cruz Biotechnology Inc.) were used as negative controls. Gastric ulcer tissue with mucosal proliferation served as the internal positive control. IL-11 and IL-11R $\alpha$ expressions were classified into three categories depending on the percentage of cells stained: -, $0-10 \%$ positive cells;,$+ 10-50 \%$ positive tumor cells; and,$++>50 \%$ positive tumor cells.

Reagents and cell culture. Recombinant human IL-11 (rhIL-11) (Genetics Institute, Andover, MA, USA) was diluted in cell culture medium. DLD-1, HT-29, Caco-2, Lovo, and Colo320DM cell lines derived from human colon cancer, were obtained from American Type Culture Collection (Manassas, VA, USA). DLD-1, HT-29, Caco-2, Lovo, and Colo-320DM cell lines were maintained in RPMI-1640, McCoy's 5a, minimum essential medium, Ham's F12, and Dulbecco's modified Eagle's medium, respectively (all media were purchased from Invitrogen Corp., Carlsbad, CA, USA). DLD-1 and Colo-320DM supplemented with heat inactivated $10 \%$ fetal calf serum (FCS) (Invitrogen Corp.), HT-29 supplemented with heat inactivated $10 \%$ fetal bovine serum (FBS, Invitrogen Corp.), Caco-2 supplemented with heat inactivated $20 \%$ FBS and Lovo supplemented with heat inactivated $20 \%$ FCS. All cell line incubations received 2 $\mathrm{mM}$ glutamine (Invitrogen Corp.) and incubated at $37^{\circ} \mathrm{C}$ in a humidified atmosphere containing $5 \% \mathrm{CO}_{2}$.

Immunocytochemical analysis. Immunocytochemistry was performed on cells grown in 8-well glass chamber slides (Invitrogen Corp.). Cells were grown to confluence and incubated in serum-free medium alone for a further $24 \mathrm{~h}$. Cells were fixed by absolute ethanol and blocked with $50 \%$ FCS for $1 \mathrm{~h}$. The cell staining as described for the immunohistochemistry and colorization proceeded with DAB. The gp130 (H-255), polyclonal rabbit antibody was bought from Santa Cruz Biotechnology Inc.

Stimulation and inhibition. The cells were first starved in medium with reduced serum for $24 \mathrm{~h}$ before stimulating with 25,50 and $100 \mathrm{ng} / \mathrm{ml}$ rhIL-11 for $5 \mathrm{~min}$. The inhibitors, Wortmannin (Sigma-Aldrich, St. Louis, MO, USA) and PD98059 (Cell Signaling Technology, Beverly, MA, USA), were added $30 \mathrm{~min}$ prior to IL-11 stimulation at concentrations of $100 \mathrm{nM}$ and $50 \mu \mathrm{M}$, respectively. The inhibitors were dissolved in $0.001 \%$ dimethyl sulfoxide (DMSO, SigmaAldrich). This DMSO concentration was tested on each cell; no change in function was measured compared to untreated cells.

Western blot analysis. Western blot analysis was performed on human CRC tissues and CRC cell lines. The tissues and cells were then suspended in RIPA buffer $(50 \mathrm{mM}$ Tris, $150 \mathrm{mM} \mathrm{NaCl}, 1 \% \mathrm{NP}-40,1 \%$ sodium deoxycholate and 
$0.05 \%$ SDS, $\mathrm{pH} 7.4)$. The supernatant was collected, and the protein concentration was quantified using a protein assay reagent (Bio-Rad Laboratories, Hercules, CA, USA).

After boiling, the proteins $(20 \mu \mathrm{g})$ were separated by polyacrylamide gel electrophoresis (PAGE) under denaturing, and transferred to a Hybond ECL nitrocellulose membrane (Amersham Biosciences, Arlington Height, IL, USA). The membranes blocked with 5\% low-fat dried milk in TBS containing $0.1 \%$ Tween-20 (TBS-T), and then incubated for $1 \mathrm{~h}$ at room temperature with 1:500 dilutions of the antihuman IL-11 antibody (Santa Cruz Biotechnology Inc.), antihuman IL-11R $\alpha$ antibody (Santa Cruz Biotechnology Inc.) and anti-human gp130 antibody (Cell Signaling Technology, Beverly, MA), and with a 1:1,000 dilution of the p-P70 S6 RP (Ser235/236), phospho-P90 RSK (p-P90 RSK) (Ser380) and phospho-P38 MAPK (p-P38 MAPK) (Thr180/Tyr182) antibodies (Cell Signaling Technology). We processed antihuman B-actin antibody (Santa Cruz Biotechnology) as an indicator of the amounts of protein loaded. The membranes were incubated for $1 \mathrm{~h}$ with a 1:1,000 dilution of horseradishperoxidase-conjugated donkey anti-rabbit immunoglobulin G (Santa Cruz Biotechnology Inc.). The membranes were developed with a horseradish peroxidase chemiluminescence detection reagent (ECL Plus System, Amersham Biosciences), and then exposed to Hyperfilm ECL (Amersham Biosciences).

Cell growth. The cells were seeded in 6-well dishes (Coster, Cambridge, MA, USA) at $1 \times 10^{4}$ cells per well and cultured in appropriate medium containing $0.1 \%$ FCS or FBS with/ without the presence of $50 \mathrm{ng} / \mathrm{ml}$ rhIL-11. Normal rabbit IgG at the same concentration was used as a control for IL-11. To examine the growth stimulation by IL-11, the number of cells and viability were compared every 2 days using a conventional improved Neubauer hemocytometer (BrightLine, American Optical Corp., Buffalo, NY, USA) (29).

Migration/chemotaxis assay. A $0.1 \mathrm{ml}$ aliquot of HT-29 and Colo-320DM cell suspension at $1 \times 10^{5}$ cells $/ \mathrm{ml}$ was seeded to the upper chamber of transwell filters ( $8 \mu \mathrm{m}$ pore) (Corning Inc., Corning, NY, USA), which was transferred to wells containing buffer with rhIL-11 or Wortmannin. 0.1\% FBScontaining medium was added to the lower chamber and incubated for $18 \mathrm{~h}$ at $37^{\circ} \mathrm{C}$. Non-migrating cells that remained on the upper surface of the filter were removed, and the remaining cells on the lower surface of the filter were fixed with $100 \%$ methanol, stained and counted under a light microscope in five different fields (Nikon E400, x200). Assays were performed in triplicate.

Matrigel invasion assay. The Matrigel invasion assay was carried out according to the manufacturer's instructions (BD Biosciences, Palo Alto, CA, USA). A $0.5 \mathrm{ml}$ aliquot of HT-29 cell suspension at $1 \times 10^{5}$ cells $/ \mathrm{ml}$ was seeded in the upper chamber of Matrigel-coated transwell filters ( $8 \mu \mathrm{m}$ pore), which were transferred to wells containing buffer with rhIL-11, FBS or Wortmannin. The conditioned medium without serum was added to the lower chamber and incubated for 72 h. Fixation, staining and counting as described for the migration and chemotaxis assay.
Statistical analysis. The StatView II program (Abacus Concepts, Inc., Berkeley, CA, USA) was used for statistical analyses. Analyses comparing the degrees of IL-11 or IL-11R $\alpha$ expressions were performed by the Mann-Whitney $U$ and Spearman's tests.

\section{Results}

Expression of IL-11 and IL-11Ra in human CRC tissuel immunohistochemistry. We have summarized the immunohistochemical results in Table I in the expressions in human colorectal adenocarcinoma and adenoma. Normal colonic epithelium, fibroblasts and endothelial cells in stromal tissue of the tumor expressed IL-11 and IL-11R $\alpha$, although these expressions were very weak. Among 24 cases of adenoma, 15 cases $(62.5 \%)$ expressed IL-11 and only 8 cases $(33.3 \%)$ of adenoma expressed IL-11R $\alpha$. There were significant differences in IL-11 and IL-11R $\alpha$ expressions between adenoma and adenocarcinoma, particularly in the expression of IL-11R $\alpha$ ( $\mathrm{p}=0.0025$ and $\mathrm{p}<0.0001$, respectively).

The expressed IL-11 was localized in the cytoplasm of the cancer cells (Fig. 1A). The expressed IL-11R $\alpha$ was localized in the membrane of cancer cells (Fig. 1B). In IL-11 and IL-11R $\alpha$ expression, the invasive parts of the primary tumor were intensely stained, as contrasted with the superficial area of the tumor in almost cases of invasive carcinomas. The invasion grade was assigned according to the TNM and Dukes' staging systems. In many cases, both IL-11 and IL-11R $\alpha$ were expressed simultaneously in the carcinoma cell itself.

CRC cells revealed a statistically significant correlation between IL-11R $\alpha$ expression and the depth of invasion ( $\mathrm{p}=0.0059$ in the TNM staging and $\mathrm{p}=0.0239$ in the Dukes' staging). There was significant correlation between IL-11R $\alpha$ expression and lymphatic invasion $(\mathrm{p}=0.0058)$. However, there were no correlation between the expression of IL-11R $\alpha$ and the differentiation, lymph node metastasis and venous invasion of carcinoma. IL-11 expression in CRC did not correlate with these clinicopathological features (Table I).

Expression of IL-11, IL-11Ra, gp130, p-P70 S6 RP, p-P90 RSK and p-P38 MAPK in human CRC, adenoma and normal colorectal mucosal tissue/Western blot. The expressions of IL-11 by CRC were examined by Western blot analysis (Fig. 1C). Lanes 1 and 3 were human colorectal adenoma tissues, and lanes 2 and 4 were normal colorectal mucosa corresponding to the tumor tissues of lanes 1 and 3 , respectively. Lanes 5 and 7 were CRC tissues, which were graded as T4 and/or Dukes' D. Lanes 6 and 8 were normal colorectal mucosa corresponding to the tumor tissues of lanes 5 and 7 , respectively. The IL-11, IL-11R $\alpha$ and gp130 were clearly detected in the two human CRC tissues. The expression of IL-11, IL-11R $\alpha$ and gp130 were also detected in the other lanes, but their expressions were weaker than in CRCs.

The p-P70 S6 RP and p-P90 RSK were clearly detected in the two CRCs. However, adenomas and normal colorectal mucosa faintly expressed p-P70 S6 RP and p-P90 RSK. p-P38 MAPK was also clearly detected in the two human CRC tissues. p-P38 MAPK was also detected in adenomas and normal colorectal mucosa, but the expression was weaker than in CRCs. Moreover, the expressions of IL-11, IL-11R $\alpha$, 
Table I. IL-11/IL-11R expression in colorectal adenocarcinoma (103 cases).

\begin{tabular}{|c|c|c|c|c|c|c|c|}
\hline & \multirow[b]{2}{*}{$\mathrm{n}$} & \multicolumn{3}{|c|}{ IL-11 (\%) } & \multicolumn{3}{|c|}{ IL-11R $\alpha(\%)$} \\
\hline & & - & + & ++ & - & + & ++ \\
\hline Tobular adenoma & & $\mathrm{p}=0.0025^{\mathrm{a}}$ & & & $\mathrm{p}<0.0001^{\mathrm{b}}$ & & \\
\hline & 24 & $9(37.5)$ & $7(29.2)$ & $8(33.3)$ & $16(66.7)$ & $8(33.3)$ & $0(0.0)$ \\
\hline Total carcinoma & 103 & $14(13.6)$ & $23(22.3)$ & $66(64.1)$ & $25(24.3)$ & $28(27.2)$ & $50(48.5)$ \\
\hline Differentiation & & $\mathrm{n} . \mathrm{s}$ & & & n.s & & \\
\hline Wel & 51 & $7(13.7)$ & $13(25.5)$ & $31(60.8)$ & $15(29.4)$ & $14(27.5)$ & $22(43.1)$ \\
\hline Mod & 41 & $5(12.2)$ & $7(17.1)$ & $29(70.7)$ & $6(14.6)$ & $13(31.7)$ & $22(53.7)$ \\
\hline Por & 5 & $0(0.0)$ & $1(20.0)$ & $4(80.0)$ & $1(20.0)$ & $0 .(0.0)$ & $4(80.0)$ \\
\hline Muc & 6 & $2(33.3)$ & $2(33.3)$ & $2(33.3)$ & $3(50.0)$ & $1(16.7)$ & $2(33.3)$ \\
\hline Deapth of invasion & & n.s & & & $\mathrm{p}=0.0059$ & & \\
\hline $\mathrm{T} 1$ & 32 & $5(15.6)$ & $9(28.1)$ & $18(56.3)$ & $13(40.6)$ & $11(34.4)$ & $8(25.0)$ \\
\hline $\mathrm{T} 2$ & 9 & $1(11.1)$ & $2(22.2)$ & $6(66.7)$ & $2(22.2)$ & $2(22.2)$ & $5(55.6)$ \\
\hline $\mathrm{T} 3$ & 43 & $6(14.0)$ & 8 (18.6) & $29(67.4)$ & $7(16.3)$ & $9(20.9)$ & $27(62.8)$ \\
\hline $\mathrm{T} 4$ & 19 & $2(10.5)$ & $4(21.1)$ & $13(68.4)$ & $3(15.8)$ & $6(31.6)$ & $10(52.6)$ \\
\hline Lymph node metastasis & & $\mathrm{n} . \mathrm{s}$ & & & n.s & & \\
\hline Present & 32 & $5(15.6)$ & $6(18.8)$ & $21(65.6)$ & 7 (21.9) & $7(21.9)$ & $18(56.3)$ \\
\hline Absent & 71 & $9(12.7)$ & $17(23.9)$ & $45(63.4)$ & $18(25.4)$ & $21(29.6)$ & $32(45.1)$ \\
\hline Lymphatic invasion & & $\mathrm{n} . \mathrm{s}$ & & & $\mathrm{p}=0.0058$ & & \\
\hline Present & 68 & $10(14.7)$ & $12(17.6)$ & $46(67.6)$ & $13(19.1)$ & $15(22.1)$ & $40(58.8)$ \\
\hline Absent & 35 & $4(11.4)$ & $11(31.4)$ & $20(57.1)$ & $12(34.3)$ & $13(37.1)$ & $10(28.6)$ \\
\hline Venous invasion & & $\mathrm{n} . \mathrm{s}$ & & & $\mathrm{n} . \mathrm{s}$ & & \\
\hline Present & 40 & $5(12.5)$ & $9(22.5)$ & $26(65.0)$ & $7(17.5)$ & $10(25.0)$ & $23(57.5)$ \\
\hline Absent & 63 & $9(14.3)$ & $14(22.2)$ & $40(63.5)$ & $18(28.6)$ & $18(28.6)$ & $27(42.9)$ \\
\hline Duke's stage & & $\mathrm{n} . \mathrm{s}$ & & & $\mathrm{p}=0.0239$ & & \\
\hline $\mathrm{A}$ & 40 & $5(12.5)$ & $12(30.0)$ & $23(57.5)$ & $14(35.0)$ & $14(35.0)$ & $12(30.0)$ \\
\hline $\mathrm{B}$ & 31 & $4(12.9)$ & $5(16.1)$ & $22(71.0)$ & $4(12.9)$ & $7(22.6)$ & $20(64.5)$ \\
\hline $\mathrm{C}$ & 28 & $4(14.3)$ & $5(17.9)$ & $19(67.9)$ & $6(21.4)$ & $6(21.4)$ & $16(57.1)$ \\
\hline $\mathrm{D}$ & 4 & $1(25.0)$ & $1(25.0)$ & $2(50.0)$ & $1(25.0)$ & $1(25.0)$ & $2(50.0)$ \\
\hline
\end{tabular}

${ }^{\mathrm{a}} \mathrm{A}$ significant difference between adenoma and total carcinoma in the expression of IL-11; ${ }^{\mathrm{b}} \mathrm{A}$ significant difference between adenoma and total carcinoma in the expression of IL-11R. n.s, not significant.

gp130, p-P70 S6 RP, p-P90 RSK and p-P38 MAPK in the two adenomas were of slightly higher intensity than in normal colorectal mucosa.

Expression of IL-11, IL-11R a and gp130 in CRC cell lines. The expressions of IL-11, IL-11R $\alpha$ and gp130 in five CRC cell lines, DLD-1, HT-29, Caco-2, Lovo and Colo-320DM, were examined by Western blot analysis (lane 1, DLD-1; lane 2, HT-29; lane 3, Caco-2; lane 4, Lovo; lane 5, Colo-320DM; Fig. 2A). These proteins were detected in all five human CRC cell lines. Caco-2 and Lovo cells highly expressed IL-11, while other cell lines expressed IL-11 at low level. HT-29 and Colo-320DM cells expressed IL-11R $\alpha$ at high levels, while other cells expressed IL-11R $\alpha$ at low level. Two CRC cell lines, HT-29 and Colo-320DM, were also examined by immunocytochemistry (Fig. 2B1-3, HT-29 and B4-6, Colo$320 \mathrm{DM})$. The expressions of IL-11, IL-11R $\alpha$ and gp130 were detected in both CRC cell lines. IL-11 was localized in the cytoplasm (Fig. 2B1 and B4), and IL-11R $\alpha$ and gp130 were localized in the cell membrane and cytoplasm (Fig. 2B2, 3, 5 and 6).

Activation of signal transduction elements in response to rhIL-11 stimulation. As a first step in defining the IL-11 signaling pathways, the phosphorylation by IL-11 of the PI3 kinase, P70 S6 RP and the MAP kinases, P90RSK and P38 was determined. The cells were stimulated with $50 \mathrm{ng} / \mathrm{ml}$ of rhIL-11 for $5 \mathrm{~min}$ and extracted protein for different time periods $(0,5,10,15,30 \mathrm{~min}, 1,3,6,9$ and $12 \mathrm{~h})$. In two CRC cell lines, HT-29 and Colo-320DM, IL-11 had different effects 

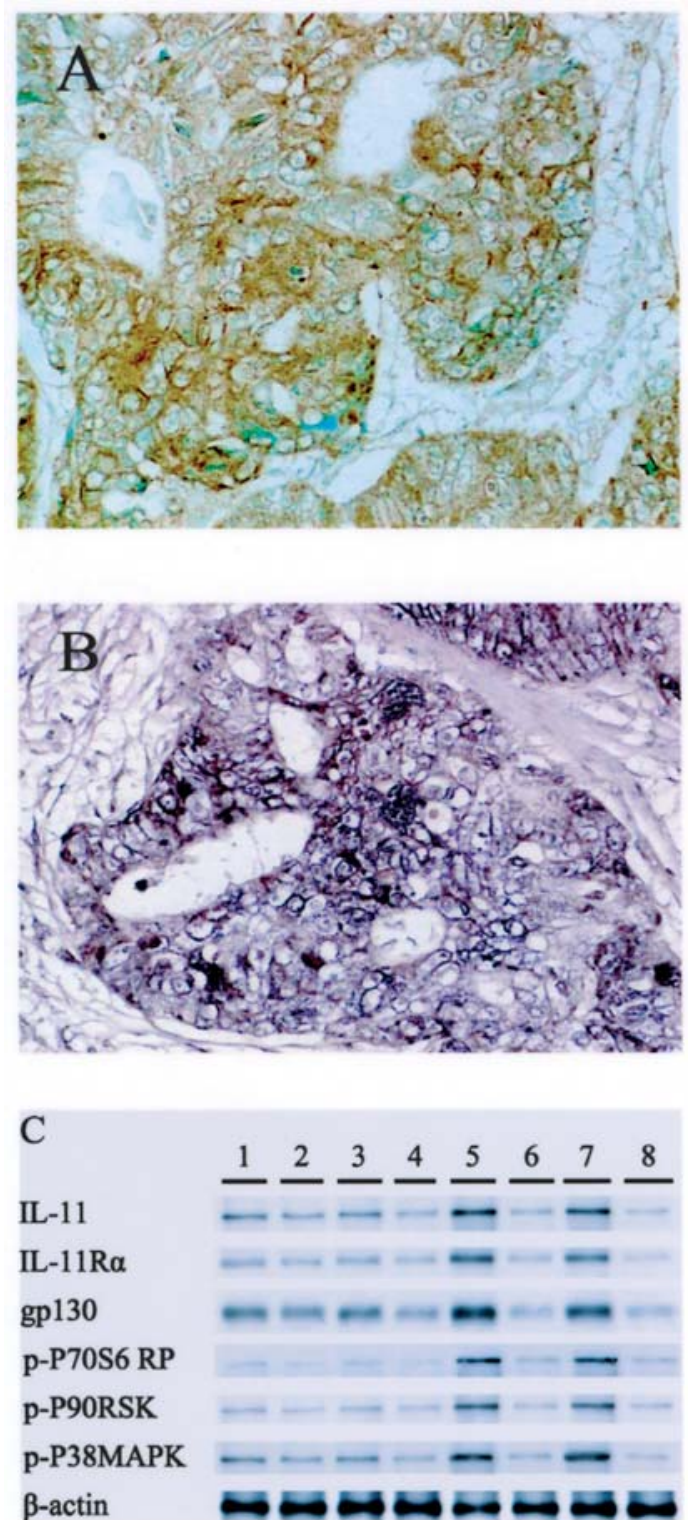

Figure 1. The investigation of IL-11/IL-11R $\alpha$, activated PI3K, and activated MAPK in human CRC tissues. Immunohistochemical staining in human colorectal carcinoma (A, IL-11 and B, IL-11R $\alpha$ ). (A, x400, DAB staining, $\mathrm{B}, \mathrm{x} 400$, alkaline-phosphatase staining) Western blot analysis for IL-11, IL-11R $\alpha$, gp130, p-P70 S6 RP, p-P90 RSK and p-P38 MAPK in human $\mathrm{CRC}$, adenoma and normal colorectal mucosa (C). Lanes 5 and 7 showed clearly expression of IL-11, IL-11R $\alpha$, gp130, p-P70 S6 RP, p-P90RSK and p-P38 MAPK. Lane 1, Case 1-adenoma; lane 2, Case 1-normal colorectal mucosa; lane 3, Case 2-adenoma; lane 4, Case 2-normal colorectal mucosa; lane 5, Case 3-CRC; lane 6, Case 3-normal colorectal mucosa; lane 7, Case 4-CRC and Lane 8, Case 4-normal colorectal mucosa. Case 3 and 4 were CRC of T4 and/or Dukes' D.

(Fig. 2C, HT-29 and D, Colo-320DM). The MAPK P38 was not phosphorylated in unstimulated cells, and IL-11 did not influence the phosphorylation state in either cell line (Fig. 2C and D). In HT-29, PI3K P70 S6 RP became phosphorylated after 5-min stimulation with $50 \mathrm{ng} / \mathrm{ml} \mathrm{rhIL-11,} \mathrm{and}$ this activation continued for at least $1 \mathrm{~h}$ (Fig. 2C). The MAPK P90RSK became phosphorylated after 5-min stimulation

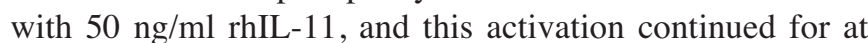
least $3 \mathrm{~h}$ (Fig. 2C). On the other hand, in Colo-320DM, the MAPK P90RSK and PI3K P70 S6 RP was only slightly
A
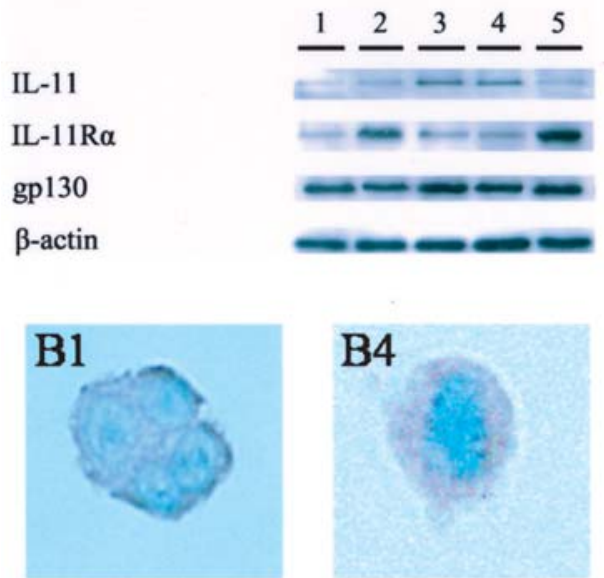

B4
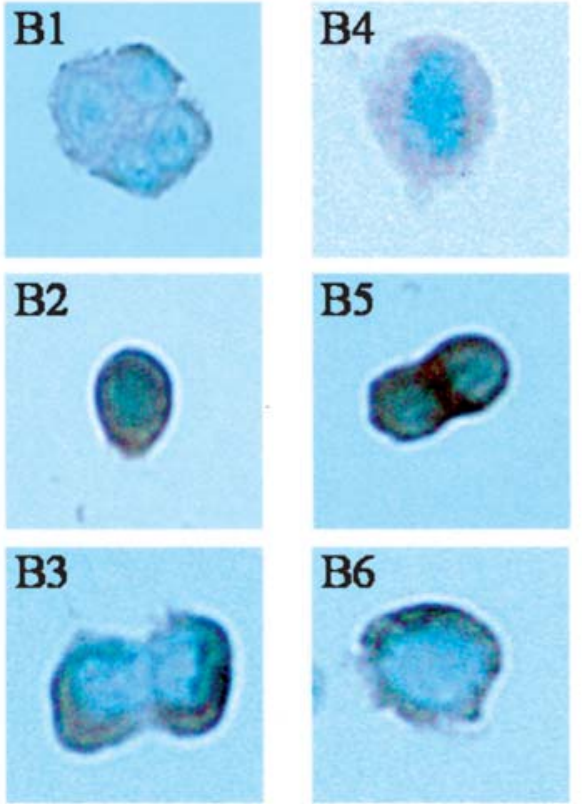

C

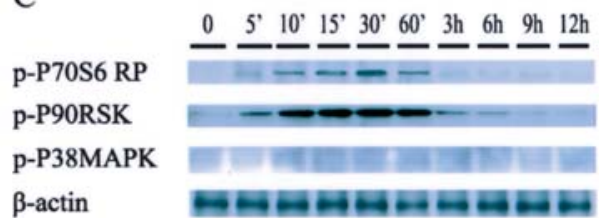

D

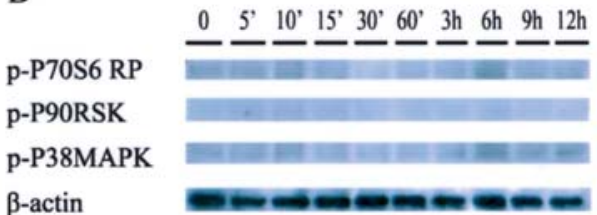

Figure 2. The investigation of IL-11/IL-11R $\alpha$, activated PI3K, and activated MAPK in human CRC cells. Western blot analysis for IL-11, IL-11R $\alpha$, gp130 and B-actin in CRC cell lines (A). Caco-2 and Lovo cells highly expressed IL-11. HT-29 and Colo-320DM cells expressed IL-11R $\alpha$ at high levels (lane 1, DLD-1; lane 2, HT-29; lane 3, Caco-2; lane 4, Lovo; lane 5, Colo-320DM). Immunocytochemistry for IL-11, IL-11R $\alpha$ and gp130 in CRC cell lines (B1-3, HT-29 and B4-6, Colo-320DM). (B1-6, x400, DAB staining) Western blot for PI3K, MAPKs pathway in human colorectal carcinoma cell lines (C, HT-29 and D, Colo-320DM). In HT-29, the PI3K P70 S6 RP and p44/p42 MAPK P90 RSK was phosphorylated by stimulation of rhIL-11 (C). In Colo-320DM, the P70 S6 RP and P90 RSK was faintly phosphorylated in unstimulated cell, and IL-11 did not influence its phosphorylation (D).

phosphorylated in unstimulated cells, and IL-11 did not influence their phosphorylation state (Fig. 2D).

Cell growth; effect of rhIL-11 on cell growth of CRC cell lines. We next examined the effect of exogenous IL-11 on the 

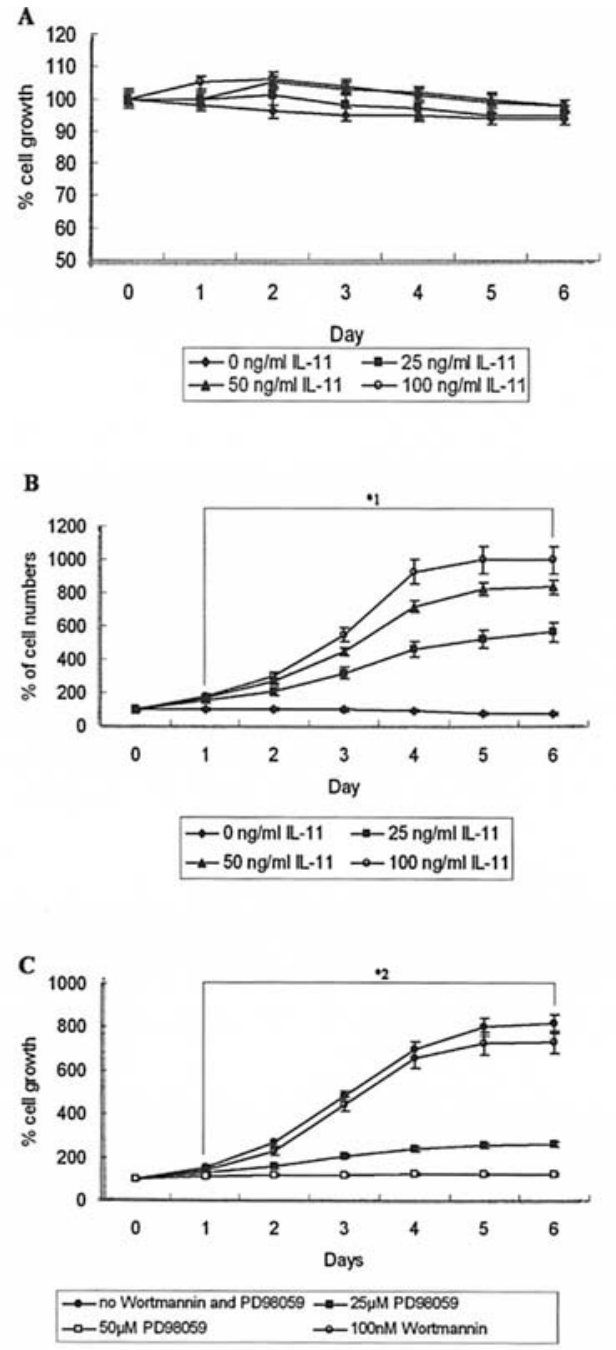

$\mathrm{D}$

\begin{tabular}{|c|c|}
\hline p-P70S6 RP & 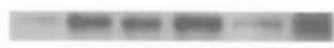 \\
\hline p-P90RSK & 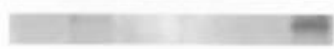 \\
\hline p-P38MAPK & \\
\hline$\beta$-actin & 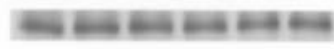 \\
\hline PD98059 $(50 \mu M)$ & -++++- \\
\hline IL-11 (50ng/ml) & -+++++ \\
\hline Time after Treatment & $0 \quad 15 \min 30 \mathrm{~min} \quad \mathrm{~h} \quad 3 \mathrm{~h} \quad 15 \min$ \\
\hline
\end{tabular}

Figure 3. Proliferative effect of IL-11 and phosphorylation of p44/p42 MAPK in human CRC cell lines. Proliferative effects of IL-11 in human CRC cells (A; Colo-320DM and B; HT-29). In Colo-320DM cells, rhIL-11 did not influence cells growth (A). In HT-29 cells, the cell numbers of each dose of rhIL-11 increased constantly until day 6 (B). In HT-29, there was a significant correlation between the dose of rhIL-11 and cell numbers $(\mathrm{p}<0.0001)$. Proliferative effect of IL-11 in HT-29 cells treated with PD98059 and Wortmannin (C). PD98059 significantly suppressed growth response in HT29 cells dose dependently $(\mathrm{p}<0.0001)$. PD98059 reduced MAP-kinase activity in HT-29 (D). *1, A significant correlation between rhIL-11 dose and cell numbers.; *2, A significant correlation between PD98059 dose and cell numbers.

growth of CRC cells. We stimulated HT-29 and Colo-320DM cells by four different doses of rhIL-11. In Colo-320DM cells, the rhIL-11 did not influence growth (Fig. 3A). HT-29 cell exhibited a significant and dose-dependent growth response to rhIL-11 ( $<<0.0001)$ (Fig. 3B). To study the effect

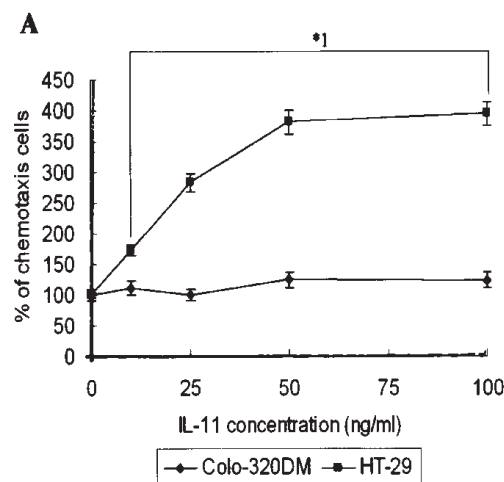

B

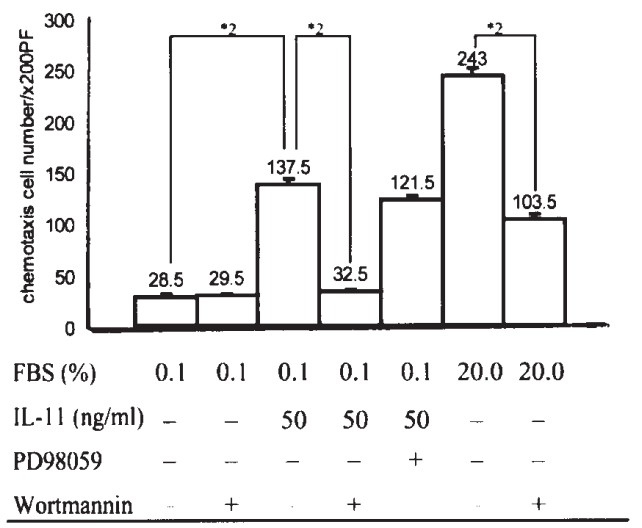

Figure 4. Chemotactic effect of IL-11 in human CRC cell lines. Chemotaxis assay in human colorectal carcinoma cells (A). Compared with Colo-320DM, HT-29 exhibited significant and dose-dependent chemotactic responses to rhIL-11 up to $50 \mathrm{ng} / \mathrm{ml}(\mathrm{p}<0.0001)$. Chemotaxis assay in HT-29 treated with Wortmannin $(100 \mathrm{nM})$ and PD98059 $(50 \mu \mathrm{M})(\mathrm{B})$. The treatment of rhIL-11 up-regulated the number of cells undergoing chemotaxis $(\mathrm{p}<0.0001)$. Wortmannin suppressed the chemotactic response in HT-29 cells that were up-regulated by rhIL-11 and also $20 \%$ FBS $(\mathrm{p}<0.0001) .{ }^{*} 1$, A significant correlation between Colo-320 and HT-29 cell numbers; *2, A significant suppression and/or upregulation.

of IL-11 on the classical MAPK pathway which acts through p44/p42 MAPK and PI3K in HT-29, the growth response was investigated. The p44/p42 MAPK inhibitor, PD98059, significantly suppressed the growth response of $50 \mathrm{ng} / \mathrm{ml}$ rhIL-11 in HT-29 cells in a dose-dependent manner $(\mathrm{p}<0.0001)$ (Fig. 3C). Meanwhile, the PI3K inhibitor, Wortmannin, did not suppress growth response in HT-29 cells (Fig. 3C). In Western blot analysis, the phosphorylation of P90 RSK was induced by stimulation with rhIL-11 in the absence but not in the presence of PD98059 in HT-29 cells (Fig. 3D). PD98059 did not influence the state of P70 S6 RP and P38 MAPK.

Chemotaxis and invasion assay of CRC cells in response to rhIL-11. Transwell migration and matrigel invasion assays were performed to examine the mobilizing effect of rhIL-11 on Colo-320DM and HT-29 colorectal carcinoma cells. Fig. 4A shows the chemotactic response of CRC cells to various concentrations of rhIL-11. Compared with Colo-320DM cells, HT-29 cells exhibited significant and dose-dependent chemotactic responses to rhIL-11 $(\mathrm{p}<0.0001)$. To study the effect of IL-11 on the PI3K pathway in HT-29, the chemotactic response was investigated (Fig. 4B). The treatment of rhIL-11 
A
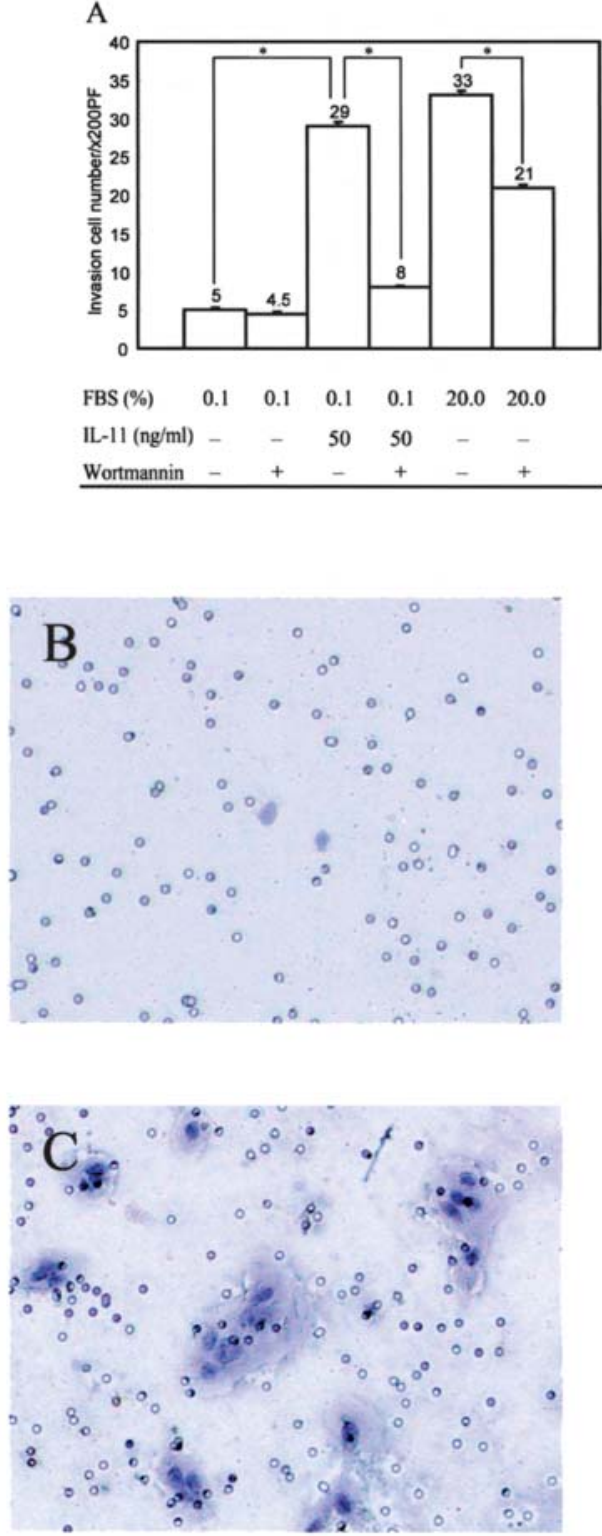

\section{D}

\begin{tabular}{|c|c|}
\hline p-P70S6 RP & 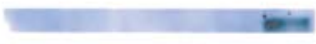 \\
\hline p-P90RSK & 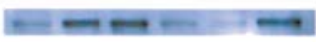 \\
\hline p-P38MAPK & \\
\hline$\beta$-actin & $\omega \infty \mathrm{men}$ \\
\hline Wortmannin $(100 \mathrm{nM})$ & ++ \\
\hline IL-11 (50ng/ml) & $+\quad+$ \\
\hline Time after Treatment & $15 \min 30 \min 1 \mathrm{~h} \quad 3 \mathrm{~h} \quad 15 \min$ \\
\hline
\end{tabular}

Figure 5. Invasion effect of IL-11 in human CRC cell lines. Invasion assay in HT-29 treated with Wortmannin (A-C). B, invaded cells with IL-11 $0 \mathrm{ng} / \mathrm{ml}$ with $0.1 \%$ FBS (x200, hematoxylin colorization). C, invaded cell with IL-11 $50 \mathrm{ng} / \mathrm{ml}$ with $0.1 \%$ FBS (x200, hematoxylin). HT-29 cells exhibited high invasion responses, in a dose-dependent fashion, to rhIL-11 ( $\mathrm{p}<0.0001)(\mathrm{A}-\mathrm{C})$. Wortmannin $(100 \mathrm{nM})$ suppressed invasion responses that were upregulated by rhIL-11 and/or 20\% FBS ( $\mathrm{p}<0.0001$, respectively) (A). Wortmannin reduced PI3 kinase activity which was induced by rhIL-11 in HT-29 (D). * A significant suppression and/or up-regulation.

up-regulated the number of cells undergoing chemotaxis $(\mathrm{p}<0.0001)$. The PI3K inhibitor, Wortmannin significantly suppressed the chemotactic response in HT-29 cells ( $\mathrm{p}<0.0001)$. Wortmannin also suppressed a chemotactic response in $20 \%$ FBS $(\mathrm{p}<0.0001)$. However, the classical MAPK pathway inhibitor PD98059 did not suppress the chemotactic response in HT-29.

Next, we performed in vitro invasion assays to investigate the effects of these chemotactic responses on the invasiveness of CRC cells (Fig. 5A-C). Fig. 5A shows the number of cells that invaded through a reconstituted basement membrane in each of the five fields. We found that HT-29 cells exhibited highly invasive responses, in a dose-dependent fashion, to rhIL-11 through the reconstituted basement membrane $(\mathrm{p}<0.0001)$. To study the effect of IL-11 on the PI3K pathway in HT-29 cell, the invasive response was investigated. The PI $3 \mathrm{~K}$ inhibitor, Wortmannin, significantly suppressed the invasive response in HT-29 cells $(\mathrm{p}<0.0001)$. Wortmannin also inhibited the invasion activity in $20 \% \mathrm{FBS}$ $(\mathrm{p}<0.01)$. Next, to investigate the effect of Wortmannin on the PI3K pathway in CRC cells, the HT-29 cell was preincubated with Wortmannin in HT-29. Phosphorylation of P70 S6 RP was induced by stimulation with rhIL-11 in the absence but not the presence of Wortmannin (Fig. 5D). Wortmannin did not influence the state of P90 RSK p44/p42 MAPK and P38 MAPK.

\section{Discussion}

A multi-step carcinogenesis has been proposed for CRC, a theory that is generally accepted (30). Our results suggest that IL-11 and IL-11R $\alpha$ have a role in the lymphatic and venous invasions of colorectal carcinoma, as one of the steps in carcinogenesis and in the development of invasive characteristics. Poorly differentiated types of adenocarcinomas show invasive spreading histologically, and have poorer prognoses than well differentiated types (31). It has been reported that there was a significant correlation between the type of histological differentiation and prognosis (32), but in this study, there was not significant correlation between IL-11 and IL-11R $\alpha$ expression and histological differentiation of the tumor. Our results suggested that IL-11 and IL-11R $\alpha$ might play an important role not in the differentiation but in the invasion of CRC.

The p44/p42 MAPK pathway is mostly known to be involved in proliferation, although several groups have stated that in some cell types it could also be involved in migration $(23,24,33)$. The PI3K pathway is said to be an antiapoptotic pathway in myeloma (21), although several groups have found that PI3K plays a key role in migration and gradientsensing in other cell types $(19,20)$. In our study, Wortmannin, the inhibitor of the PI3K pathway, suppressed the phosphorylation of P70 S6 RP and reduced the invasion activity of CRC cell lines, and PD98059, the inhibitor of the p44/42 MAPK pathway, suppressed the phosphorylation of P90 RSK and reduced the proliferation activity of CRC cell lines. The activation of the PI3K and p44/p42 MAPK pathways by IL-11 may play an important role in the invasion and proliferation of colorectal carcinoma cells.

In clinical specimens, T4 and/or Dukes' D CRC expressed high intensity of IL-11, IL-11R $\alpha$ and gp130, compared with adenomas and normal colorectal mucosa. In T4 and/or 
Dukes' D CRC, phosphorylation of P70 S6 RP, P90 RSK and P38 MAPK were detected. However, other clinical samples also showed faint phosphorylation of these proteins. Moreover, adenomas had slightly higher phosphorylation of these proteins compared with normal colorectal mucosa. IL-11 did not phosphorylate P38 MAPK in CRC cell lines, so the phosphorylation of P38 MAPK in the clinical specimens may be induced by other cytokines and/or stimulations. These data suggest that IL-11/IL-11R $\alpha$ signaling is needed for invasion and proliferation activity of carcinoma.

In conclusion, we demonstrated that the IL-11/IL-11R system regulated the activation of PI3K and MAPK pathways and up-regulated the invasion and proliferation activity of CRC cells. Further identification of tyrosine kinases and/or other pathways associated with IL-11 is needed to fully understand the mechanisms of the invasion and proliferation of colorectal carcinoma cells associated with this cytokine.

\section{Acknowledgements}

We are grateful to Mr Toshiyuki Kawada (Nagasaki University Graduate School of Biomedical Sciences) for his excellent immunohistochemical and molecular biological assistance.

\section{References}

1. Steinberg SM, Barwick KW and Stablein DM: Importance of tumor pathology and morphology in patients with surgically resected colon cancer. Findings from the Gastrointestinal Tumor Study Group. Cancer 58: 1340-1345, 1986.

2. Ming SC (ed): Pathology of the Gastrointestinal Tract. Williams \& Wilkins Press, NJ, pp879-883, 1998

3. Newland RC, Dent OF, Lyttle MN, Chapuis PH and Bokey EL: Pathologic determinants of survival associated with colorectal cancer with lymph node metastases. A multivariate analysis of 579 patients. Cancer 73: 2076-2082, 1994.

4. Goseki N, Koike M and Yoshida M: Histopathologic characteristics of early stage esophageal carcinoma. A comparative study with gastric carcinoma. Cancer 69: 1088-1093, 1992.

5. Du XX and Williams DA: Interleukin-11: review of molecular, cell biology and clinical use. Blood 89: 3897-3908, 1997.

6. Lacroix M, Siwek B, Marie PJ and Body JJ: Production and regulation of interleukin-11 by breast cancer cells. Cancer Lett 127: 29-35, 1998

7. Hanavadi S, Martin TA, Watkins G, Mansel RE and Jiang WG: Expression of interleukin 11 and its receptor and their prognostic value in human breast cancer. Ann Surg Oncol, 2006.

8. Deutscher N, Bataille F, Hausmann M, Kiessling S, MullerNewen G, Leeb SN, Herfarth H, Heinrich PC, Scholmerich J and Rogler G: Functional expression of the interleukin-11 receptor alpha-chain in normal colonic epithelium and colon cancer. Int J Colorectal Dis: 1-9, 2005.

9. Yamazumi K, Nakayama T, Kusaba T, Wen CY, Yoshizaki A, Yakata Y, Nagayasu T and Sekine I: Expression of interleukin-11 and interleukin-11 receptor alpha in human colorectal adenocarcinoma; immunohistochemical analyses and correlation with clinicopathological factors. World J Gastroenterol 12: 317-321, 2006.

10. Paul S, Bennet F, Calvetti J, Kelleher K, Wood C, O'Hara R Jr, Leqary A, Sibley B, Clark S, Williams D and Yang YC: Molecular cloning of a cDNA encoding interleukin-11, a stromal cell-derived lymphopoietic and hematopoietic cytokine. Proc Natl Acad Sci USA 87: 7512-7516, 1990.

11. Du XX, Liu Q, Yang Z, Orazi A, Rescoria FJ, Grosfeld JL and Williams DA: Protective effects of interleukin-11 in a murine model of ischemic bowel necrosis. Am J Physiol 272: G545-G552, 1997.

12. Girasole G, Passeri G, Jilka RL and Manolagas SC: Interleukin-11: a new cytokine critical for osteoclast development. J Clin Invest 93: 1516-1524, 1994.
13. Keller DC, Du XX, Srour EF, Hoffman R and Williams DA: Interleukin-11 inhibits adipogenesis and stimulates myelopoiesis in human long-term marrow cultures. Blood 82: 1428-1435, 1993

14. Orazi A, Du X, Yan Z, Kashai M and Williams DA: Interleukin-11 prevents apoptosis and accelerates recovery of small intestinal mucosa in mice treated with combined chemotherapy and radiation. Lab Invest 75: 33-42, 1996.

15. Heinrich PC, Behrmann I, Muller-Newen G, Schaper F and Graeve L: Interleukin-6 type cytokine signaling through the gp130/Jak/STAT pathway. Biochem J 334: 297-314, 1998.

16. Dahmen H, Horsten U, Kuster A, Jacques Y, Minvielle S, Kerr IM, Ciliberto G, Paonessa G, Heinrich PC and MullerNewen G: Activation of the signal transducer gp130 by interleukin-11 and interleukin-6 is mediated by similar molecular interactions. Biochem J 331: 695-702, 1998.

17. Fuhrer DK and Yang YC: Activation of src-family protein tyrosine kinases and phosphatidylinositol-3 kinase in 3T3-L1 mouse preadipocytes by interleukin-11. Exp Hematol 24: 195-203, 1996.

18. Yin T, Yasukawa K, Taga T, Kishimoto T and Yang YC: Identification of a 130-kilodalton tyrosine-phosphorylated protein induced by interleukin-11 as JAK2 tyrosine kinase, which associates with gp130 signal transducer. Exp Hematol 22: 467-472, 1994.

19. Comer FI and Parent CA: PI 3-kinases and PTEN: how opposites chemoattract. Cell 109: 541-544, 2002.

20. Gerszten RE, Friedrich EB, Matsui T, Hung RR, Li L, Force T and Rosenzweig A: Role of phosphoinositide 3-kinase in monocyte recruitment under flow conditions. J Biol Chem 276: 26846-26851, 2001

21. Tu Y, Gardner A and Lichtenstein A: The phosphatidylinositol 3-kinase/AKT kinase pathway in multiple myeloma plasma cells: roles in cytokine-dependent survival and proliferative responses. Cancer Res 60: 6763-6770, 2000.

22. Rouse J, Cohen P, Trigon S, Morange M, Alonso LA, Zamanillo D, Hunt T and Nebreda AR: A novel kinase cascade triggered by stress and heat shock that stimulates MAPKAP kinase-2 and phosphorylation of the small heat shock proteins. Cell 78: 1027-1037, 1994.

23. Sturgill TW, Ray LB, Erikson E and Maller JL: Insulin-stimulated MAP-2 kinase phosphorylates and activates ribosomal protein S6 kinase II. Nature 334: 715-718, 1988.

24. Wu J, Harrison JK, Dent P, Lynch KR, Weber MJ and Sturgill TW: Identification and characterization of a new mammalian mitogen-activated protein kinase kinase, MKK2. Mol Cell Biol 13: 4539-4548, 1993.

25. Freshney NW, Rawlinson L, Guesdon F, Jones E, Cowley S, Hsuan J and Saklatvala J: Interleukin-1 activates a novel protein kinase cascade that results in the phosphorylation of hsp27. Cell 78: 1039-1049, 1994.

26. Page DL (ed): Colon and rectum. In: American Joint Committee on Cancer. AJCC Cancer Staging Manual. 6th edition. Springer Press, New York, pp113-124, 2002.

27. Sobin LH (ed): Histological typing of intestinal tumors.In: World Health Organization International Histological Classification of Tumors. Springer Press, Berlin, pp8-10, 1989.

28. Dukes CE: The surgical pathology of rectal cancer. J Clin Pathol 2: 95-98, 1949 .

29. Knippenberg PH (ed): Isolated Hepatocytes: Preparation, Properties and Applications. Elsevier Press, Amsterdam, pp15-58, 1991.

30. Vogelstein B, Fearon ER, Hamilton SR, Kern SE, Preisinger AC, Leppert M, Nakamura Y, White R, Smits AM and Bos JL: Genetic alterations during colorectal-tumor development. N Engl J Med 9: 525-532, 1988.

31. Chen TR, Hay RJ and Macy ML: Karyotype consistency in human colorectal carcinoma cell lines established in vitro. Cancer Genet Cytogenet 6: 93-117, 1982.

32. Trainer DL, Kline T, McCabe FL, Faucette LF, Field J, Chaikin M, Anzano M, Rieman D, Hoffstein S and Li DJ: Biological characterization and oncogene expression in human colorectal carcinoma cell lines. Int J Cancer 41: 287-296, 1988.

33. Wu J, Michel H, Rossomando A, Haystead T, Shabanowitz, J, Hunt DF and Sturgill TW: Renaturation and partialpeptide sequencing of mitogen-activated protein kinase (MAP kinase) activator from rabbit skeletal muscle. Biochem J 285: 701-705, 1992. 